\title{
Dynamic Modeling and Simulation of an Offshore Combined Heat and Power (CHP) Plant
}

\author{
Jairo Rúa Rubén M. Montañés Luca Riboldi Lars O. Nord \\ Department of Energy and Process Engineering, NTNU - Norwegian University of Science and Technology, \\ Trondheim - Norway, jairo.r.pazos@ntnu.no
}

\begin{abstract}
The design and analyis of a flexible combined heat and power (CHP) system where the exhaust of two gas turbines is utilized as the heat source for a steam Rankine cycle is proposed in this paper. The case of study is the Johan Castberg off-shore facility, located in the Barents Sea, Norway. The steady-state design of the CHP system is developed with a specialized software based on the peak demand conditions of the platform, which account for $58 \mathrm{MW}$ of electric and shaft power, and $52 \mathrm{MW}$ of heat. A multi-objective optimization approach is followed in order to attain optimal designs where high efficiency is achieved while keeping reasonable weight to power ratios. Once the power cycle design is selected, the detailed dynamic modeling of the different components integrating the cycle is presented and implemented in Modelica language. Steady-state design and off-design validation of the thermal power plant model is carried out, and preliminary results are presented to show the ability of the dynamic model to provide reasonable information of the steam bottoming cycle transient operation.
\end{abstract}

Keywords: dynamic process simulation, steam Rankine cycle, waste heat recovery, multi-objective optimization, offshore flexible operation, Modelica, genetic algorithm.

\section{Introduction}

The implementation of mitigation policies, like $\mathrm{CO}_{2}$ emission taxation (Ministry of Environment, 2012) and the participation of Norway in the European Union emission trading system (ETS), has motivated the improvement of heat and power generation systems employed in offshore oil and gas facilities. The petroleum sector is responsible of $30 \%$ of the total $\mathrm{CO}_{2}$ emissions of Norway, with the simple gas turbine cycles currently employed in the Norwegian continental shelf being the source of more than $80 \%$ of the $\mathrm{CO}_{2}$ emissions generated by this sector (Norwegian Ministry of Petroleum and Energy, 2017).

New power generation systems with better performance and lower emissions are needed in order to mitigate the effects of the oil and gas facilities on the environment, and make this industry more competitive from an economic point of view. Combined cycles are regarded as a promising and feasible alternative to the traditional gas turbines due to their higher efficiency and to their technology matu- rity (Kloster, 1999). Low weight and operation flexibility are also fundamental criteria in the design of combined cycles. The cost of offshore facilities increases rapidly with the weight while the operation as a stand-alone systems requires that the fluctuations in power and heat demand must be entirely matched by the power system. A tradeoff among compactness, flexibility and high efficiency may be achieved, even during off-design conditions, if the traditional heat recovery steam generator with several pressures levels and steam drums is replaced by a oncethrough steam generator (OTSG) for offshore applications (Nord and Bolland, 2012, 2013). The low weight and flexibility of this basic configuration allows the installation of different tailor-made alternatives, which enhances the utilization of combined cycles for waste heat recovery applications as different objectives may be achieved with different bottoming cycles (Pierobon et al., 2014a).

In addition to the design and off-design performance, the analysis of unsteady operation is specially useful for offshore combined cycles since they work in transient mode due to the variations in heat and power demand and fuel composition. Dynamic modeling and simulation of these systems may predict possible imbalances between power generation and consumption, and may identify unstable scenarios where a reliable and optimum performance cannot be guaranteed. Moreover, critical scenarios as the trip of a gas turbine may be analyzed, ensuring the operation robustness and safety of the power plant (Benato et al., 2014).

The utilization of dynamic models can also improve the design of control systems and strategies (Montañés et al., 2017). Traditional steady design procedures aim to achieve the highest possible efficiency or the correct balance between efficiency and weight to power ratio. Unsteady performance is not considered at this stage but it is studied when the control strategy is being designed, leading to excessively aggressive control configurations where the off-design operation is worsen as a result of the limitations established by the dynamic operation. Evaluating the unsteady performance of a certain power plant design by means of a dynamic model may discard its implementation due to the violation of specific performance constraints, albeit its possible high efficiency or low weight during nominal operation (Pierobon et al., 2014b). Therefore, the integration of dynamic models in the selection 
criteria of a power cycle design can improve the overall performance of the system. Dynamic response and effectiveness of the control strategy of a thermodynamic cycle for waste heat recovery applications may be tested under certain off-design conditions if a dynamic model is developed for such purpose (Mazzi et al., 2015). A dynamic model of a small-scale ORC was also employed to propose and compare three different control strategies, showing that with the correct control strategy the efficiency remains in reasonable levels even if the heat source conditions are modified (Quoilin et al., 2011).

Dynamic models can also be utilized to analyze critical scenarios where extreme conditions for the equipment may be expected and steady-state models do not provide enough information. As a result, new start-up conditions with higher thermal gradients but similar maximum temperatures that allow to halve the time required to generate the maximum power may be achieved (Alobaid et al., 2008). A reduction in the start-up time without increasing the stress limits was also found by (Casella and Pretolani, 2006), who also proposed another strategy that reduces the stress peak extending the lifetime without increasing the start-up time.

This paper aims at developing dynamic models for power plant components and testing their performance during transient operation of a combined heat and power plant. In addition, preliminary results of the operation flexibility of the selected CHP design, i.e. the adaptability to fast operation changes, are shown. The description of the case study and the methodology followed to assess the dynamic performance of the CHP plant are presented in Section 2. The modeling approach utilized for the development of the steady and dynamic model is covered in Section 3. Results of the dynamic simulations are reported and discussed in Section 4. Concluding remarks are given in Section 5.

\section{Case study and methodology}

The case study is the power system needed in the Johan Castberg field, located in the Barents sea. The heat and power requirements have been assessed for its lifetime, expecting heat demands between $32 \mathrm{MW}$ and $52 \mathrm{MW}$, and power demands ranging from $42 \mathrm{MW}$ to $58 \mathrm{MW}$ (Statoil ASA, 2016).

A combined heat and power plant is proposed as an alternative power generation system where heat from the exhaust gases of two gas turbines is utilized as a heat source for a steam bottoming cycle. Figure 1 shows a simplified layout of the CHP plant. Two GE LM2500+G4 gas turbines produce the majority of the required power while the energy contained in their exhaust gases is recovered in a OTSG to produce the steam utilized in the bottoming cycle. The design point specifications of this gas turbine model are specified in Table 1. The high ratios between the heat and power demand entail a challenge for the steam Rankine cycle and a back-pressure steam turbine has to
Table 1. Design point specifications of the GE LM2500+G4 gas turbine.

\begin{tabular}{lc}
\hline Variable & Design point value \\
\hline Net power output $[\mathrm{MW}]$ & 32.50 \\
Net efficiency [\%] & 36.50 \\
Exhaust gas flow rate $[\mathrm{kg} / \mathrm{s}]$ & 89.90 \\
Exhaust temperature $\left[{ }^{\circ} \mathrm{C}\right]$ & 552 \\
Net heat rate $[\mathrm{kJ} / \mathrm{kWh}]$ & 9867 \\
Gas turbine inlet $\Delta p[\mathrm{mbar}]$ & 10 \\
Gas turbine exhaust $\Delta p[\mathrm{mbar}]$ & 10 \\
Ambient temperature $\left[{ }^{\circ} \mathrm{C}\right]$ & 10 \\
Ambient pressure $[\mathrm{bar}]$ & 1.013 \\
Air humidity [\%] & 60.00 \\
Gas turbine fuel & Production gas \\
\hline
\end{tabular}

be utilized. Thus, the superheated steam produced in the OTSG is not totally expanded in order to have enough energy to produce the required process heat. A fraction of this steam is sent to one of the condensers of the selected parallel configuration where pressurized water at $150^{\circ} \mathrm{C}$ is produced to meet the heat demand. The remaining superheated steam is condensed in the second branch condenser using sea water as cooling fluid.

The large variations in heat and power demand that may be experienced in the offshore facility and the fact that the power generation system operates as a stand-alone system require that the CHP plant operates in a flexible manner. Therefore, the dynamic operation of the proposed design must be assessed in order to ensure the correct functioning of the power plant under varying conditions. In addition, as previously mentioned, low weight and compactness are fundamental conditions in this kind of thermal power systems. Thus, a dynamic analysis of a preliminary design of the CHP plant obtained from a multi-objective optimization was carried out in order to verify that the combined cycle performs correctly during unsteady operation.

\subsection{Steady state design and multi-objective optimization}

The life-time assessment of the energy requirements expected for the offshore oil field shows that maximum demands of heat and power may occur simultaneously (Statoil ASA, 2016). Hence, the nominal operation point was selected to correspond to peak demands of heat and power, $52 \mathrm{MW}$ and $58 \mathrm{MW}$ respectively, in order to ensure that these conditions are met by the power generation system.

Once the design conditions of the CHP plant were defined, the steady state modeling and design was carried out utilizing the specialized software Thermoflex (Thermoflow Inc, 2016). The selection of this tool was based on its reliability, as it has been extensively tested and validated with industrial data. The thermodynamic states were determined by means of mass and energy conservation laws, and the boundary conditions imposed to the 


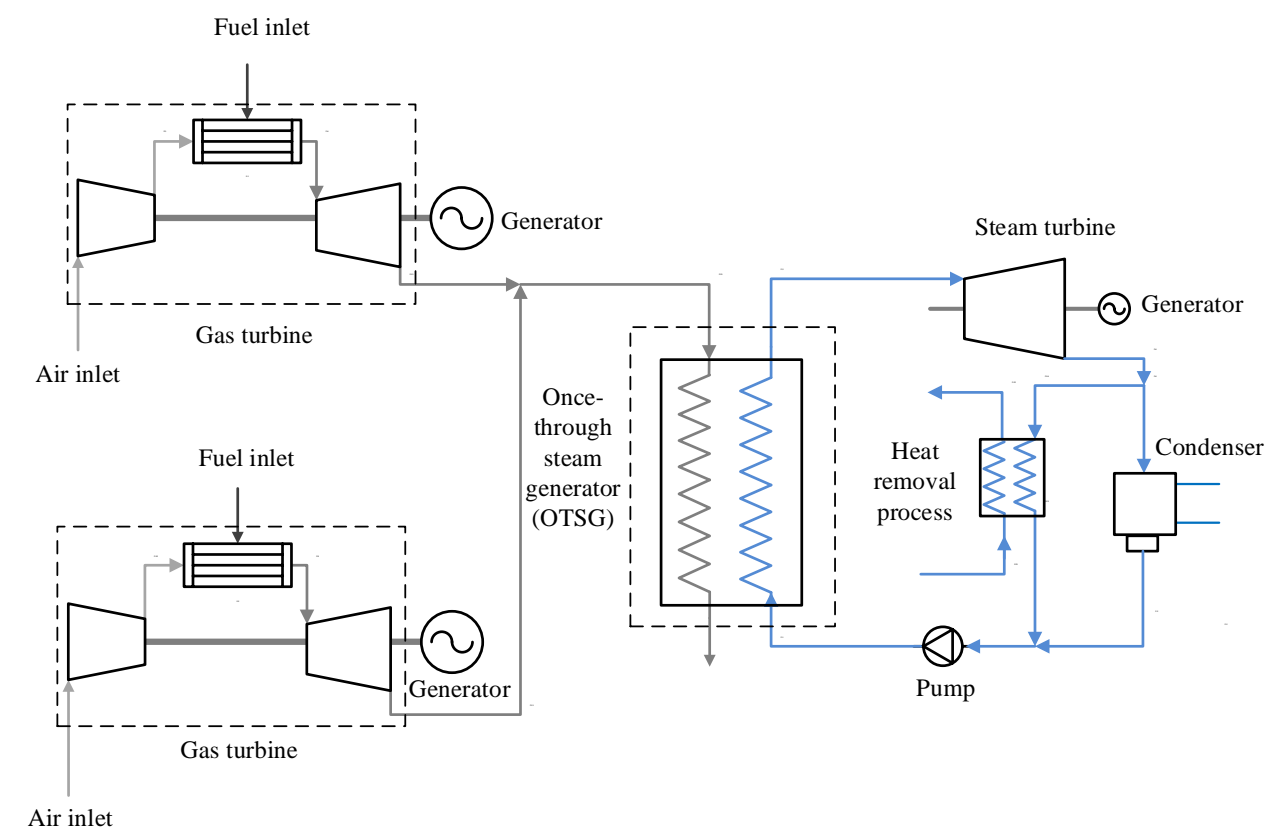

Figure 1. Simplified layout of the proposed power generation system for the offshore facility in Johan Castberg field.

model. From this data, the sizing of the components of the steam Rankine cycle was carried out. Subsequently, a constrained multi-objective optimization based on a genetic algorithm included in the global optimization MATLAB toolbox (MathWorks, 2017) was performed, where the heat rate and the weight to power ratio were the objective functions to be minimized (Riboldi and Nord, 2017). The selected decision variables during the optimization procedure were the steam turbine inlet pressure, $p_{\text {steam }}$, and temperature, $T_{\text {steam }}$, the pinch point difference in the evaporating section of the OTSG, $\Delta T_{\text {pinch }}$, and the gas turbine load of one turbine, $G T_{2, \text { load }}$, utilizing the other unit to match the power demand. The bounds of the decision variables are reported in Table 2. A population size of 150 was selected while a maximum of 15 generations were allowed. Crossover and tolerance were set equal to 0,8 and $10^{-3}$ respectively. The stopping criterion utilized in this optimization procedure was either the exceedance in the maximum number of generations or having an average change in the spread of the Pareto front lower than the tolerance selected. A two-dimensional Pareto front was obtained as a result of this procedure. The solution that provides the best balance for the requirements of the offshore facility was selected.

\subsection{Dynamic model development and un- steady performance assessment}

A dynamic model of the preliminary CHP plant design must be built in order to evaluate its operation under varying scenarios, e.g. load changes or unit trips. The dynamic modeling language Modelica was utilized for the development of such model, as its object-oriented nature and the existence of specialized libraries ease the implementation
Table 2. Lower and upper bounds of the selected decision variables.

\begin{tabular}{lcc}
\hline Decision variables & Lower bound & Upper bound \\
\hline$p_{\text {steam }}[\mathrm{bar}]$ & 10 & 40 \\
$T_{\text {steam }}\left[{ }^{\circ} \mathrm{C}\right]$ & 400 & 515 \\
$\Delta T_{\text {pinch }}\left[{ }^{\circ} \mathrm{C}\right]$ & 10 & 30 \\
$G T_{2, \text { load }}[\%]$ & 75 & 94 \\
\hline
\end{tabular}

of transient conservation laws, correlations and the component dimensions calculated in the previous step. In this work, the open-source library specialized in power plants ThermoPower (Casella and Leva, 2003) was employed.

Open-loop simulations, i.e. without control, may be carried out from this model in order to achieve a deeper understanding of the intrinsic unsteady behavior of the cycle. However, a suitable control strategy with appropriate tuning parameters was implemented in the dynamic model in order to simulate real plant operation. The steam turbine was operated in sliding pressure mode, while the mass flow rate of steam through the primary condenser was utilized to regulate the temperature of the pressurized water employed as a process heat means. The water level of this condenser was controlled in order to ensure a stable operation of the system, whereas the water level of the secondary condenser was allowed to vary, absorbing the fluctuations of the process heat section and acting as a water buffer under off-design loads. In addition, the live steam temperature was controlled by means of the mass flow rate circulating in the Rankine cycle. PI controllers were utilized in order to ensure a stable operation. 


\section{Modeling Approach}

\subsection{Gas turbine model}

Gas turbines' dynamics were not considered as their transient operation is much faster than that of the steam Rankine cycle. Instead, the gas turbines were modeled with validated quasi-static models, and the exhaust gas stream was utilized as boundary conditions to the dynamic process model (Montañés et al., 2017). Off-design conditions were obtained from the compressor and turbine maps of the gas turbine validated by Thermoflex, and a variable characteristic that simulates the fluctuating exhaust gas conditions was implemented in the dynamic model.

\subsection{OTSG model}

The different sections of the OTSG were modeled as three individual heat exchangers: an economizer, a oncethrough boiler (OTB), and a superheater. The preheating of the liquid fluid takes place in the economizer, where sufficient difference between the boiling point and the outlet temperature, i.e. an approach point, was left in order to ensure that no evaporation occurred in this component during off-design operation. The OTB mainly modeled the vaporization of the working fluid, but it also included the preheating of the water leaving the economizer until saturation conditions and some superheating of the steam during design operation. The final degree of superheating of the steam produced in the OTB is achieved in the superheater.

Each of the heat exchangers was spatially discretized in ( $\mathrm{N}-1)$ cells, where mass and energy conservation laws, and heat transfer correlations were applied (see Figure 2). Momentum conservation law was not included as the inertia of the fluid was neglected and the pressure drops were modeled as lumped parameters at the outlet of each component.

The mass and energy conservation laws were equally modeled in the three heat exchangers and for both gas and water/steam sides. The discretized mass conservation expression for a one-dimensional flow is:

$$
\sum_{j=1}^{N-1} \frac{d M_{j}}{d t}=\dot{m}_{\text {in }}-\dot{m}_{\text {out }}
$$

where $\dot{m}_{\text {in }}$ and $\dot{m}_{\text {out }}$ are, respectively, the mass flow rates at the inlet and outlet of each heat exchanger; and $M_{j}$ is the mass of fluid in each cell, given by:

$$
\frac{d M_{j}}{d t}=V_{j} \cdot\left(\left.\overline{\frac{\partial \rho}{\partial h}}\right|_{j} \cdot \frac{d h_{j}^{\prime}}{d t}+\left.\overline{\frac{\partial \rho}{\partial p}}\right|_{j} \cdot \frac{d p}{d t}\right)
$$

being $V_{j}$ the volume of each cell, and with the average partial derivatives of density respect to enthalpy and pressure, $\left.\frac{\overline{\partial \rho}}{\partial h}\right|_{j}$ and $\left.\frac{\overline{\partial \rho}}{\partial p}\right|_{j}$, in the center of the cell calculated from their nodes values.

$$
\begin{aligned}
& \left.\frac{\overline{\partial \rho}}{\partial h}\right|_{j}=\frac{1}{2}\left(\left.\frac{\partial \rho}{\partial h}\right|_{j+1}+\left.\frac{\partial \rho}{\partial h}\right|_{j}\right) \\
& \overline{\left.\frac{\partial \rho}{\partial p}\right|_{j}}=\frac{1}{2}\left(\left.\frac{\partial \rho}{\partial p}\right|_{j+1}+\left.\frac{\partial \rho}{\partial p}\right|_{j}\right)
\end{aligned}
$$

The one-dimensional spatially discretized energy conservation law is:

$$
V_{j} \cdot \bar{\rho}_{j} \cdot \frac{d h_{j}^{\prime}}{d t}-\overline{\dot{m}}_{j} \cdot\left(h_{j+1}-h_{j}\right)=\dot{Q}_{j}+V_{j} \cdot \frac{d p}{d t}
$$

where $\bar{\rho}_{j}$ is the average density of each discretization, $h_{j}^{\prime}$ is the enthalpy state variable at the center of the cell, $h_{j}$ the fluid specific enthalpy evaluated at the nodes, $\dot{Q}_{j}$ the heat flow from or to the wall, $p$ is the pressure, and $\overline{\dot{m}}_{j}$ the mass flow rate in each cell, defined as:

$$
\overline{\dot{m}}_{j}=\dot{m}_{i n}-\sum_{j=1}^{j-1} \frac{d M_{j}}{d t}-\frac{1}{2} \frac{d M_{j}}{d t}
$$

The heat flows between the hot and cold fluids, subindex $h$ and $c$ respectively, and the metal tube were calculated in the center of each cell as:

$$
\begin{array}{r}
\dot{Q}_{j, h}=\gamma_{h} \cdot A_{j, h} \cdot\left(\frac{T_{j+1, h}+T_{j, h}}{2}-T_{w a l l, j, h}\right) \\
\dot{Q}_{j, c}=\gamma_{c} \cdot A_{j, c} \cdot\left(\frac{T_{j+1, c}+T_{j, c}}{2}-T_{\text {wall }, j, c}\right)
\end{array}
$$

being $T_{j+1}$ and $T_{j}$ the temperatures at the nodes, $T_{\text {wall }, j}$ the temperature of the wall in the outer or inner tube surfaces evaluated at the center of the cell, $A_{j}$ the heat transfer surface for each fluid, and $\gamma$ the convection heat transfer coefficient. In the gas side this coefficient can be calculated with the relation (Incropera et al., 2007):

$$
\gamma=\gamma_{\text {nom }}\left(\frac{\dot{m}}{\dot{m}_{\text {nom }}}\right)^{0.6}
$$

where $\gamma_{\text {nom }}$ is the convection heat transfer coefficient during steady-state nominal operation utilized in Thermoflex.

In the water side of the economizer and superheater constant heat transfer coefficients were employed since they were calculated in the design stage and the main thermal resistance was the heat transfer in the gas side. However, the value of this coefficient in the water side of the OTB varies substantially due to the phase changes that occur, and an overall coefficient could not be utilized. Thus, the Dittus-Boelter correlation with constant heat transfer value consisting on the saturated boiling region heat transfer coefficient was employed:

$$
\gamma=0.023 \frac{k}{D_{\text {hyd }}} \operatorname{Re}^{0.8} \operatorname{Pr}^{0.4}
$$




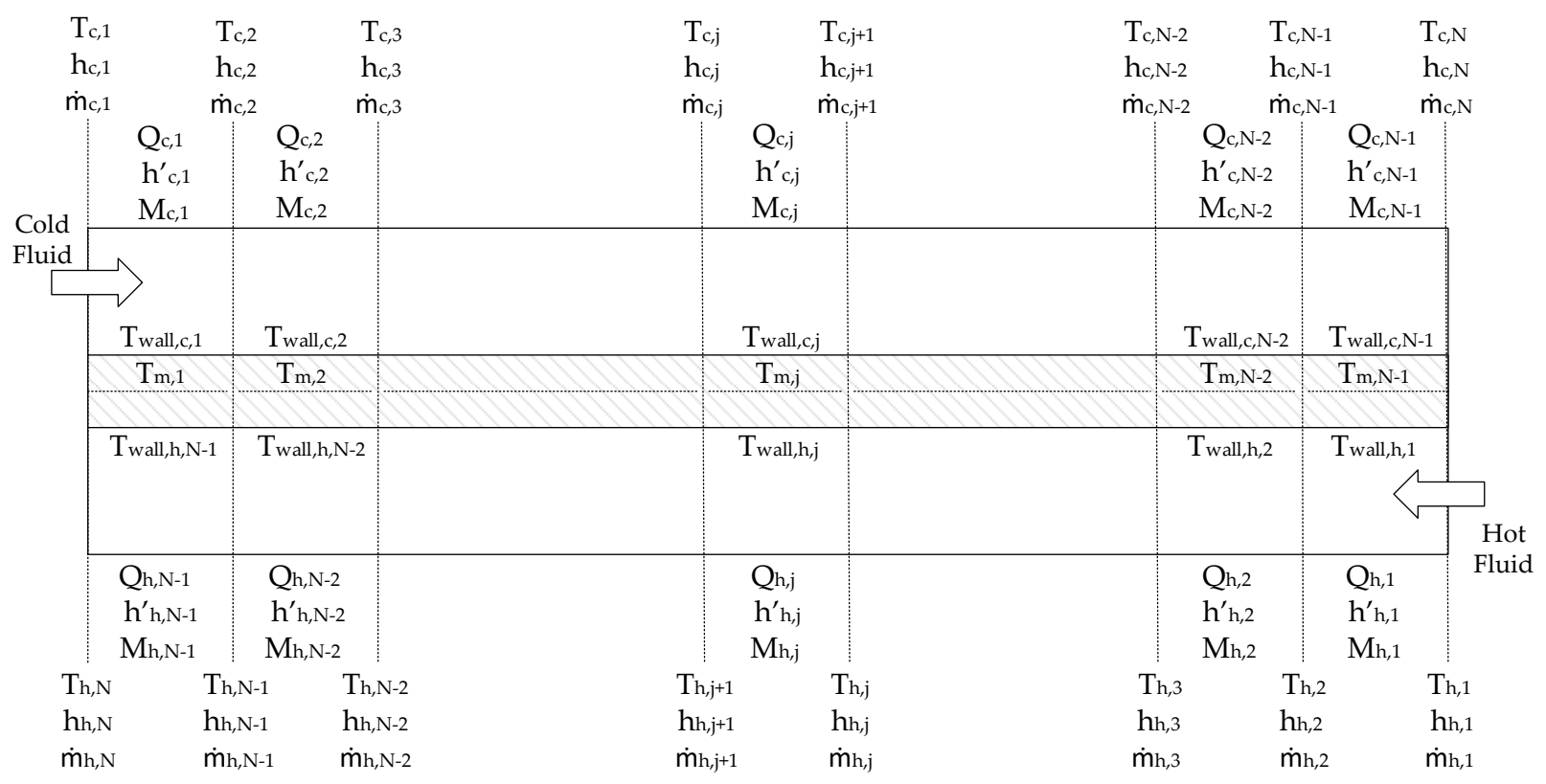

Figure 2. Modeling paradigm of the once-through steam generator.

where k is the thermal conductivity of the fluid, $D_{\text {hyd }}$ is the hydraulic diameter, $R e$ is the Reynolds number, and $\mathrm{Pr}$ is the Prandtl number.

The heat capacity of the metal tubes that accounts for the thermal inertia of the heat exchangers during dynamic operation is included in the model as:

$$
V_{m} \cdot \rho_{m} \cdot C p_{m} \cdot \frac{d T_{m}}{d t}=\dot{Q}_{h}+\dot{Q}_{c}
$$

Here, $V_{m}$ is the volume of metal, $\rho_{m}$ is the metal density, and $C p_{m}$ is the metal heat capacity. $T_{m}$ is the temperature in between both sides of the metal tube, and $\dot{Q}_{h}$ and $\dot{Q}_{c}$ are the heat flows coming from the hot and cold sides, respectively.

The heat conduction through the metal tubes is defined as:

$$
\begin{aligned}
\dot{Q}_{h} & =N t \cdot \frac{\lambda \frac{2 \pi L}{N-1} \cdot\left(T_{\text {wall }, h}-T_{m}\right)}{\log \left(\frac{2 \cdot r_{\text {ext }}}{r_{\text {ext }}+r_{\text {int }}}\right)} \\
\dot{Q}_{c} & =N t \cdot \frac{\lambda \frac{2 \pi L}{N-1} \cdot\left(T_{\text {wall }, c}-T_{m}\right)}{\log \left(\frac{r_{\text {ext }}+r_{\text {int }}}{2 \cdot r_{\text {int }}}\right)}
\end{aligned}
$$

where $N_{t}$ is the number of tubes, $L$ is the length of the tubes, $r_{\text {ext }}$ and $r_{\text {int }}$ are the external and internal radius, and $\lambda$ is the conduction coefficient of the tubes.

\subsection{Steam turbine model}

A quasy-static model of the steam turbine was utilized in this work. The dynamics of this unit are faster than those of the OTSG, and since frequency fluctuations were not analyzed, the dynamic behavior of the steam turbine was neglected. Therefore, the differential conservation equations are reduced to algebraic equations.

The steam turbine performance during off-design operation was predicted by means of Stodola's cone law (Stodola, 1927):

$$
\dot{m}_{\text {in }}=K_{t} \sqrt{\rho_{\text {in }} p_{\text {in }} \sqrt{1-\left(\frac{1}{P R}\right)^{2}}}
$$

with $K_{t}$ being the Stodola's coefficient, $\rho_{i n}$ and $p_{\text {in }}$ the density and pressure at the inlet of the steam turbine, and $P R$ the pressure ratio, defined as:

$$
P R=\frac{p_{\text {in }}}{p_{\text {out }}}
$$

where $p_{\text {out }}$ is the pressure after the expansion.

The mechanical power, $P m$, extracted by the steam turbine from the steam is obtained by:

$$
P m=\eta_{\text {mech }} \cdot \dot{w} \cdot\left(h_{\text {in }}-h_{\text {out }}\right)
$$

where $\eta_{\text {mech }}$ is the mechanical efficiency, w is the mass flow rate along the turbine, and $h_{\text {out }}$ is obtained, assuming constant isentropic efficiency $\eta_{i s o}$, from:

$$
\eta_{\text {iso }}=\frac{h_{\text {in }}-h_{\text {out }}}{h_{\text {in }}-h_{\text {iso }}}
$$




\subsection{Condenser model}

The modeled condenser is a shell and tube heat exchanger where the cooling fluid circulates within the tubes while the condensing fluid flows through the tube bundle on the shell side. The utilization of a back-pressure steam turbine implies that the steam entering the condensers is superheated. Thus, this feature must be taken into account in the model of the component.

The modeling of the cooling flow on the tube side is done similarly as in Section 3.2. Mass conservation is given by Eq. (1), whereas Eq. (5) is utilized to describe the energy balance. Heat transfer to the cooling fluid is modeled by Eq. (8) where the heat transfer coefficient is calculated by means of the Dittus-Boelter correlation (see Eq. (10)). The thermal dynamics of the metal tubes of the condenser are accounted by the utilization of Eqs. (11) and (13).

Since the working fluid enters the condenser as superheated steam, the shell side is discretized in order to account for the change in temperature and fluid properties. Saturated conditions at the outlet of the shell side and constant volume of the shell, $V_{\text {shell }}$, are set as constraints of the model. The division of this volume into sub-units, $V_{\text {shell }, j}$, is done gradually in order to obtain more accuracy at the outlet of the shell, where the density changes of the twophase mixture are abrupt and a lot of detail is required. Hence, the volume of each discretization is defined as:

$$
V_{\text {shell }, j}=\frac{V_{\text {shell }}}{2^{j}}
$$

The mass of working fluid in each volume, $M_{\text {shell }, j}$, and the energy it contains, $E_{\text {shell, }, j}$, are calculated using the average of the density, $\rho_{j}$, and the specific enthalpy, $h_{j}$, at both nodes of the cell:

$$
\begin{array}{r}
M_{\text {shell }, j}=V_{\text {shell }, j} \cdot \frac{\rho_{j+1}+\rho_{j}}{2} \\
E_{\text {shell }, j}=M_{\text {shell }, j} \cdot \frac{h_{j+1}+h_{j}}{2}-p \cdot V_{\text {shell }, j}
\end{array}
$$

Dynamic mass and energy conservation are employed to model the flow in the shell side:

$$
\begin{array}{r}
\frac{d M_{s h e l l, j}}{d t}=\dot{m}_{j}-\dot{m}_{j+1} \\
\frac{d E_{s h e l l, j}}{d t}=\dot{m}_{j} \cdot h_{j}-\dot{m}_{j+1} \cdot h_{j+1}-\dot{Q}_{j}
\end{array}
$$

where $d M_{\text {shell }, j} / d t$ and $d E_{\text {shell }, j} / d t$ are the time rate of mass and energy change in the center of the cell, $\dot{m}_{j}$ and $\dot{m}_{j+1}$ the mass flow rates evaluated at the nodes of the cell, and $\dot{Q}_{j}$ is the heat flow from the discretized volume, which is calculated from Eq. (7).

The modeling of the hotwell was done in order to account for the increase in the outlet pressure, $p_{\text {out }}$, due to the static pressure of the water column and the time rate of mass change, $\frac{d M_{\text {hotwell }}}{d t}$. Hence:

$$
\begin{gathered}
p_{\text {out }}=p_{\text {in }}-h_{\text {hotwell }} \cdot g \cdot \bar{\rho}_{\text {hotwell }} \\
\frac{d M_{\text {hotwell }}}{d t}=\dot{m}_{\text {in }}-\dot{m}_{\text {out }}
\end{gathered}
$$

being $h_{\text {hotwell }}$ the level of water, $p_{\text {in }}$ the inlet pressure, and $\bar{\rho}_{\text {hotwell }}$ the average density of the water contained in the hotwell.

In addition, the change in the outlet mass flow rate due to the accumulation of water and the increase in static pressure was modeled based on:

$$
\dot{m}_{\text {out }}=\sqrt{2 g h_{\text {hotwell }}} \cdot A_{\text {duct }} \cdot \bar{\rho}_{\text {hotwell }}
$$

with $A_{d u c t}$ being the area of the duct leaving the hotwell.

\subsection{Pump model}

A variable speed pump model was employed in this work, i.e. the mass flow rate is adapted by modifying the rotation speed. A third-order polynomial equation was utilized to describe the curves relating the mass flow to the head since the map of performance of the pump was not available. This equation was generated as a regression curve from the set of data generated by Thermofex in order to smooth the transient behavior of the pump model. The enthalpy increase through the unit was given by an energy balance. Constant efficiency during off-design conditions was assumed.

\section{Results and discussion}

\subsection{CHP plant static design}

The Pareto front of solutions of the preliminary design of the CHP plant obtained from the multi-objective optimization are shown in Figure 3. From this set of results, the most suitable alternative for the off-shore facility was chosen. Table 3 displays the main design characteristics of the selected solution.

Table 3. Nominal characteristics of the preliminary plant design.

\begin{tabular}{lc}
\hline Variable & Nominal value \\
\hline Gas turbine 1 load [\%] & 72.38 \\
Gas turbine 2 load [\%] & 85.19 \\
Steam turbine inlet pressure $[\mathrm{bar}]$ & 33.79 \\
Steam turbine inlet temperature $\left[{ }^{\circ} \mathrm{C}\right]$ & 444.20 \\
Steam turbine outlet pressure $[\mathrm{bar}]$ & 4.76 \\
OTB temperature difference $\left[{ }^{\circ} \mathrm{C}\right]$ & 20.30 \\
Efficiency [\%] & 40.81 \\
Weight $[\mathrm{kg}]$ & 207068 \\
\hline
\end{tabular}




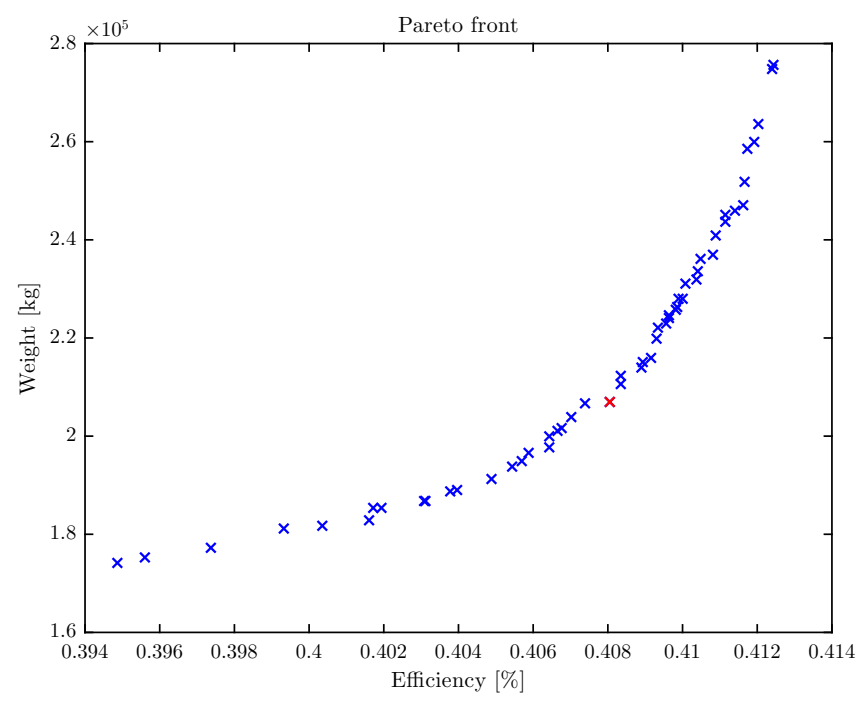

Figure 3. Pareto front of optimum solutions for the preliminary design of the CHP plant. The selected design configuration is marked in red.

\subsection{Dynamic model validation}

A thorough validation of the dynamic model was performed in order to ensure that results generated by the dynamic simulations are reliable. Dynamic data was not available, neither experimental nor generated by Thermoflex, and hence only a validation of the dynamic process model under steady-state operating conditions was carried out.

Several operation points including both design and offdesign gas turbine loads were simulated, being the results produced by the dynamic model in satisfactory agreement with the validation data. For brevity, only design validation results for the heat transferred in the OTSG sections and the primary condenser, the shaft power produced in the steam turbine, and the steam live pressure and temperature are shown (see Table 4). Extensive validation data during both design and off-design steady-state operation may be found in the literature (Rúa, 2017). Absolute errors between results generated by Dymola and Thermoflex were calculated as:

$$
\text { Error }\left.\right|_{u}=\frac{\left|u_{\text {Dymola }}-u_{\text {Thermoflex }}\right|}{u_{\text {Thermoflex }}}
$$

where $u$ may be any variable included in Table 4 .

\subsection{Dynamic simulation}

The ability of the developed combined heat and power plant model to simulate operation under transient conditions was assessed by a dynamic simulation where the load of both gas turbines was decreased from nominal operation point, i.e. $72.38 \%$ and $85.19 \%$, to $60 \%$. This was equivalent to a reduction of $20 \%$ in the power demand of the entire thermal power plant. In addition, the modification of the gas turbines load means an increase of the
Table 4. Validation results during nominal operation.

\begin{tabular}{lccc}
\hline & Dymola & Thermoflex & Error \\
\hline$\dot{Q}_{\text {economizer }}[\mathrm{MW}]$ & 10.403 & 10.343 & $0.580 \%$ \\
$\dot{Q}_{\text {evaporator }}[\mathrm{MW}]$ & 40.497 & 40.582 & $0.209 \%$ \\
$\dot{Q}_{\text {superheater }}[\mathrm{MW}]$ & 9.729 & 9.652 & $0.798 \%$ \\
$P_{m}[\mathrm{MW}]$ & 8.348 & 8.601 & $2.942 \%$ \\
$\dot{Q}_{\text {condenser }, 1}[\mathrm{MW}]$ & 52.015 & 52.050 & $0.067 \%$ \\
$T_{\text {steam }}\left[{ }^{\circ} \mathrm{C}\right]$ & 442.220 & 442.600 & $0.086 \%$ \\
$p_{\text {steam }}[\mathrm{bar}]$ & 33.809 & 33.730 & $0.234 \%$ \\
\hline
\end{tabular}

exhaust gas temperature of more than $20^{\circ} \mathrm{C}$. Therefore, two step changes, one decreasing the exhaust gas mass flow rate and the other increasing its temperature (see Figure 4), were implemented simultaneously in order to test ability of the steam cycle to handle a disturbance in the gas turbine load.

The variation of the relevant temperature variables, i.e. the steam live temperature and the process heat stream temperature, was analyzed under both open-loop conditions and with a control strategy implemented. The behavior of these two variables is represented in Figure 5. The former covers the live steam temperature while the latter shows the temperature of the process heat produced in the primary condenser. As it may be observed, both variables return to their set-point when the control strategy is applied, albeit the large change in operation conditions. However, the requirements of the offshore facility are unfulfilled when the plant is operated in open-loop conditions. A more restrictive control, i.e. with a larger controller gain, was designed for the process heat temperature in order to ensure that big fluctuations from the set point did not occur, as the pressurized high-temperature water stream is employed in the treatment of the products produced in the offshore facility and large deviations from the defined operating temperature may damage such products.

The dynamics of the controlled temperatures are slower than their open-loop counterparts. This phenomena may also be observed in Figure 6a, where the live steam pressure reaches faster a new steady-state operation point when no control is applied. This behavior is because of variation of the working fluid mass flow rate, which is the variable manipulated to control the steam live temperature, is also slow (see Figure 6b).

The water level fluctuation of both condensers is shown in Figure 7. The level of the primary condenser was controlled in order to ensure a stable operation. The control strategy applied to the primary water level responded properly to the changes experienced in the mass flow. The step changes in both exhaust gas mass flow and temperature produced, after an initial increase, a deep decrease in the steam live temperature that originated a decrease in the mass flow circulating in the bottoming cycle (see Figure 5a and Figure 6b). Thus, the water levels in the 


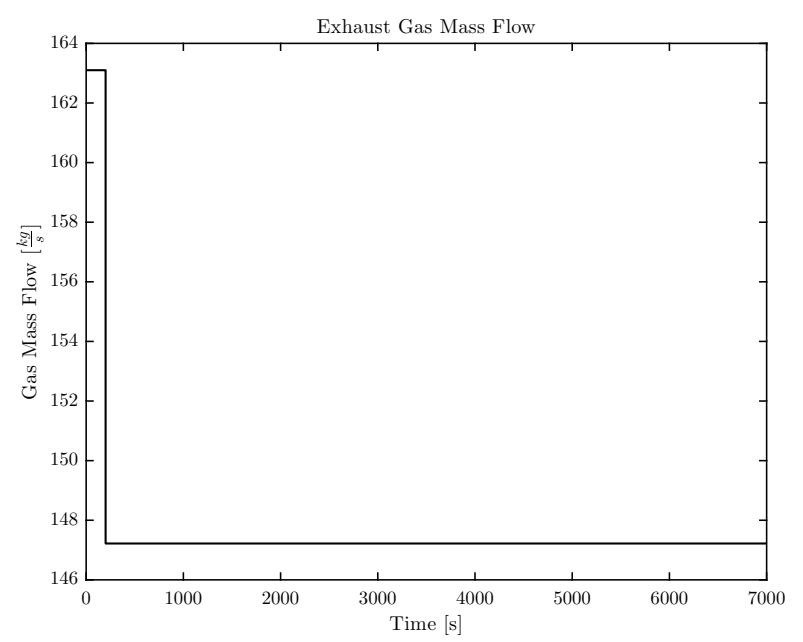

(a) Exhaust gas mass flow rate.

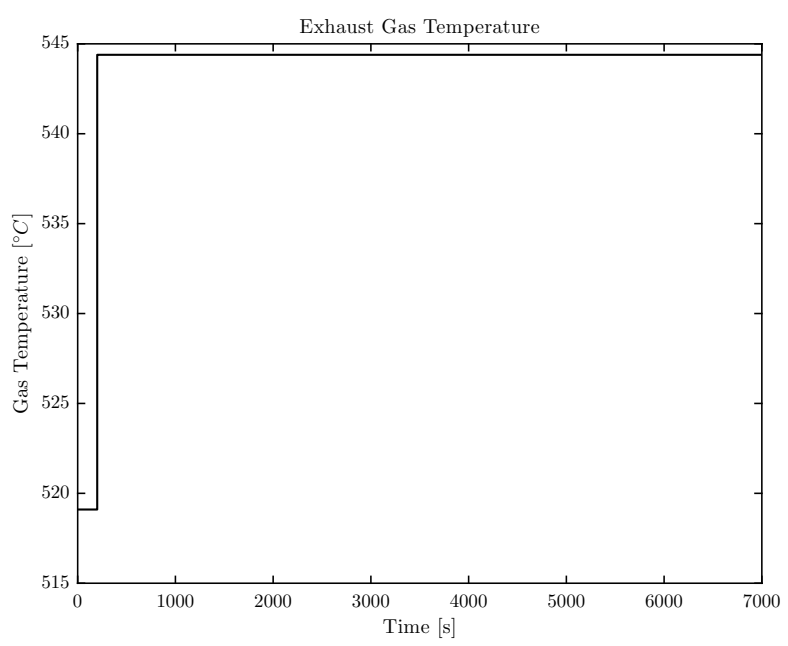

(b) Exhaust gas temperature.

Figure 4. Dynamic model boundary conditions.

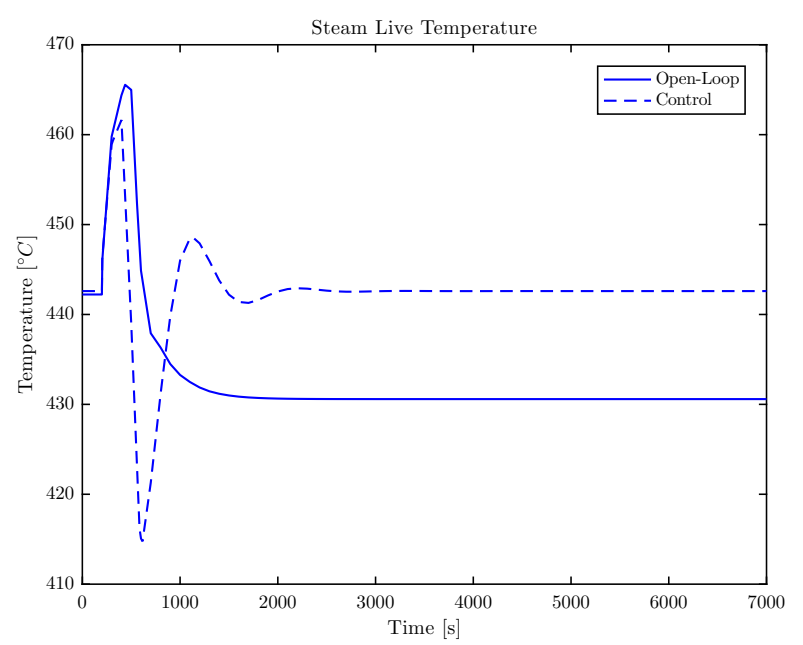

(a) Steam live temperature variation.

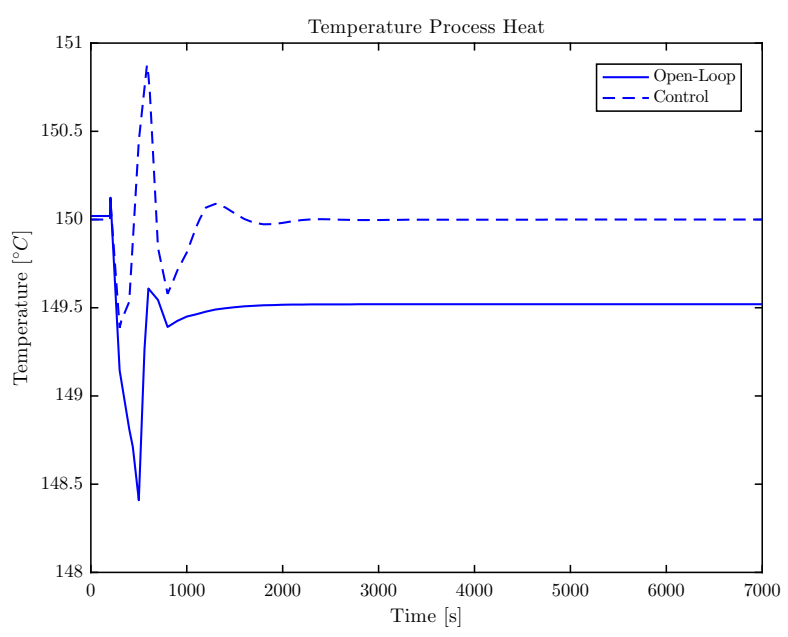

(b) Process heat temperature variation.

Figure 5. Variation of the controlled temperatures.

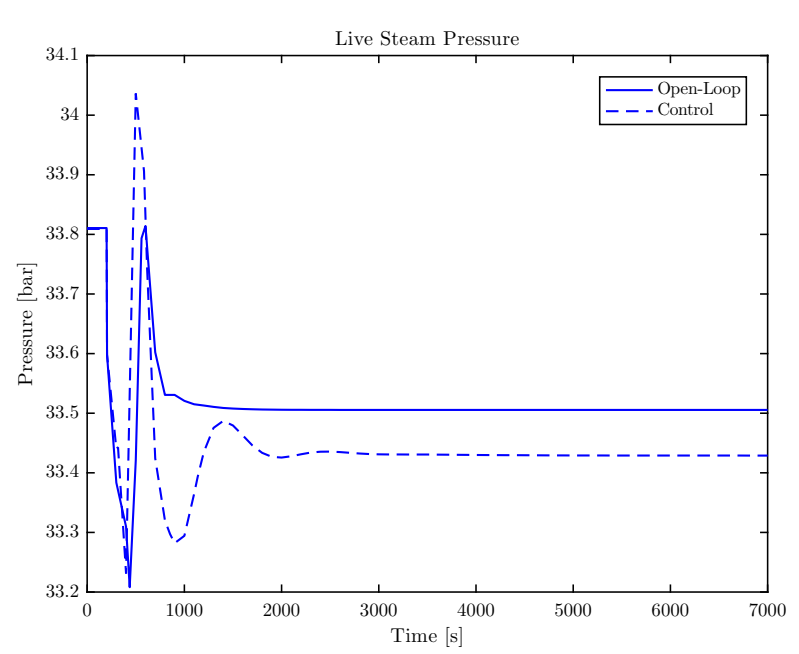

(a) Steam live pressure variation.

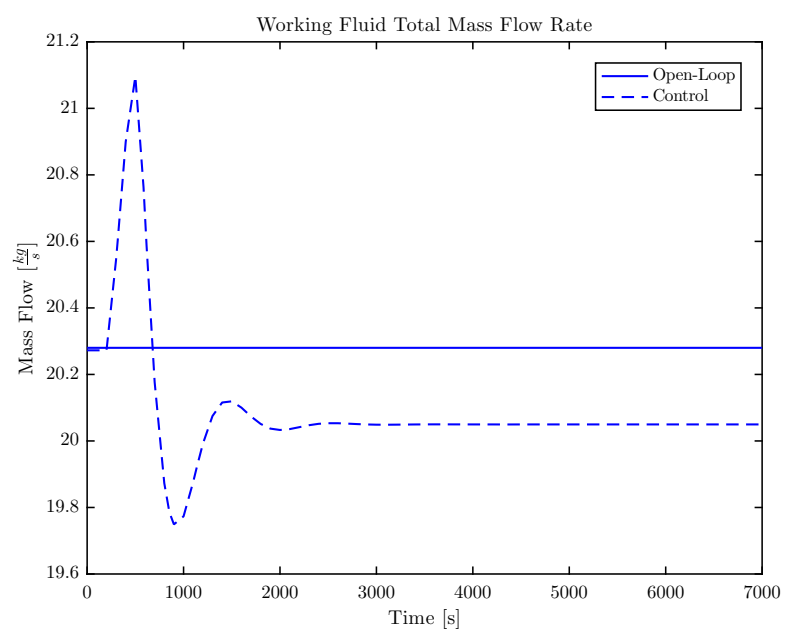

(b) Working fluid mass flow variation.

Figure 6. Variation of the working fluid mass flow and the steam live pressure. 


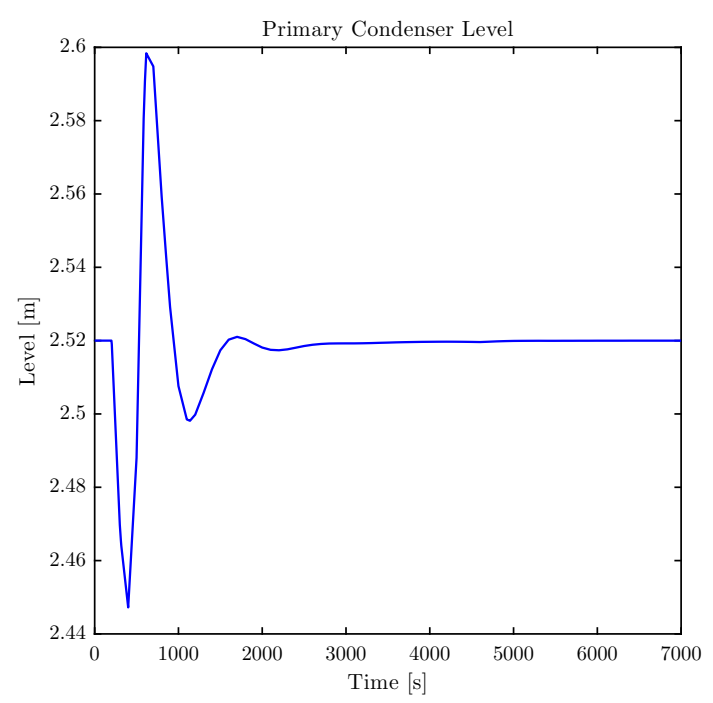

(a) Water level in the primary condenser.

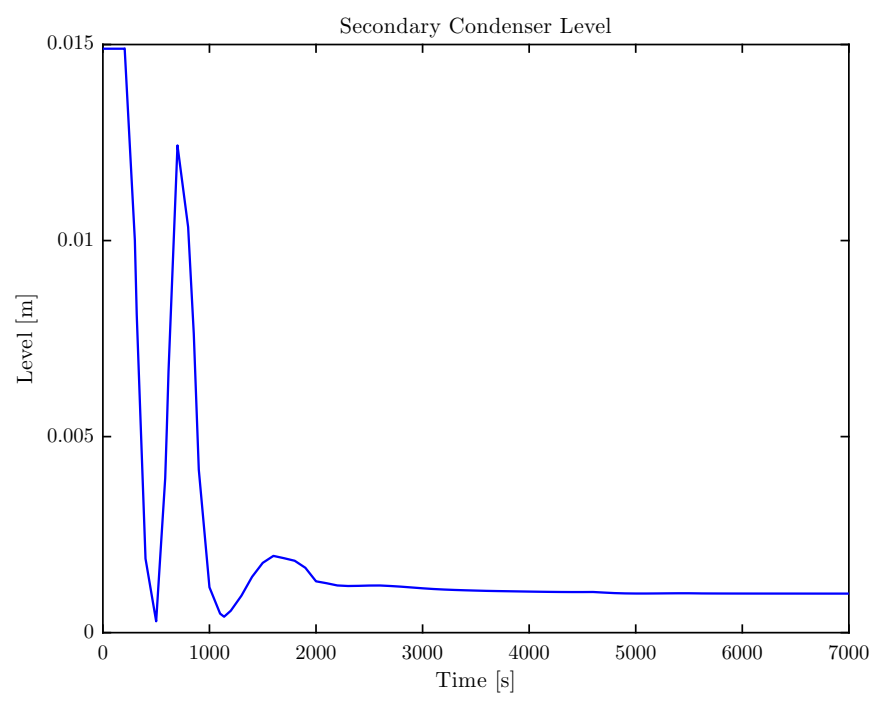

(b) Water level in the secondary condenser.

Figure 7. Water level in both condenser hotwells.

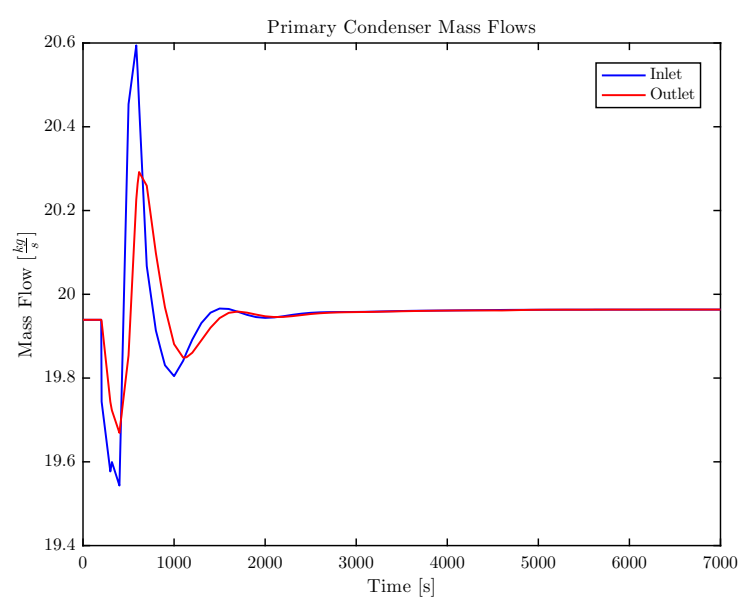

(a) Working fluid mass flow in the primary condenser.

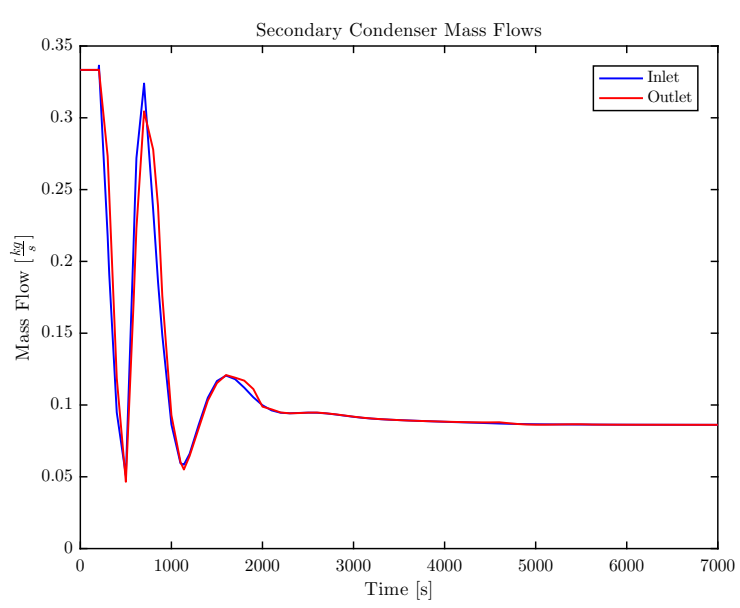

(b) Working fluid mass flow in the secondary condenser.

Figure 8. Working fluid mass flow in both condensers.

hotwells were firstly reduced and then increased as a consequence of the variations in the mass flows entering and leaving both condensers. Steady-state values of the water levels showed that the secondary condenser absorbed the fluctuations in the operating conditions originated by the reduction of the working fluid's mass flow rate.

The mass flow rate of the steam entering and the water leaving these components is represented in Figure 8. Similar trends among the water levels and mass flows in the condenser may be observed between Figure 7a and Figure $8 \mathrm{a}$, and Figure $7 \mathrm{~b}$ and Figure $8 \mathrm{~b}$, where both variables present the same pattern but the water level response is slightly shifted in time.

It is worth noting the buffering effect that the hotwell of the condensers has in the cycle, as it smears out the fluctuations (see Figure 8). This effect is specially observable in the primary condenser as the water level is larger and hence the static pressure changes are smoothed, reducing the variation in the mass flow rate of water leaving the hotwell.

\section{Conclusions}

The dynamic modeling of the components integrating an offshore combined heat and power plant was presented in this work. Preliminary results on disturbance rejection show that the developed models produce reasonable results on the transient behaviour of the studied system.

The offshore platform in Johan Castberg field was selected as case study to test the validity of the models developed. A steady-state design procedure accounting for the need of high efficiency while keeping a reduced weight was briefly presented, pointing out the demanding restrictions in offshore facilities. A dynamic model of the selected design was developed under the Modelica environment, utilizing the ThermoPower library to develop the models of the components integrating the steam Rankine 
cycle. A discretized condenser was programmed in order to accurately calculate the superheating conditions that were expected at the outlet of the back-pressure turbine.

The dynamic model of the combined heat and power plant was validated for steady-state design and off-design conditions obtained by the software Thermoflex. A preliminary evaluation of the developed models' capability to produce reasonable results under transient conditions was carried out by means of a reduction in the power demand of the combined heat and power plant, which was implemented by simultaneous step changes in the exhaust gas mass flow rate and temperature. The dynamic performance of relevant variables during the dynamic operation was shown and analyzed, showing that these models could be utilized for assessing that, with a suitable control strategy, the CHP plant would be able to produce the demanded heat at the required temperature even if changes to the nominal operation conditions of the power plant occurred. In addition, it was verified that limiting conditions, e.g. maximum temperature in the steam turbine, are not reached during unsteady performance, which is a valuable information for the operator of the plant.

The proposed assessment methodology has been applied for an offshore facility where restrictions are harder than in on-shore power plants. However, it is readily applicable to any waste heat recovery application where performance under transient conditions needs to be analyzed.

\section{References}

F. Alobaid, R. Postler, J. Ströhle, B. Epple, and K.Hyun-Gee. Modeling and investigation start-up procedures of a combined cycle power plant. Applied Energy, 85(1):1173-1189, 2008.

A. Benato, L. Pierobon, F. Haglind, and A. Stoppato. Dynamic performance of a combined gas turbine and air bottoming cycle plant for off-shore applications. In: Proceedings of the ASME 2014 12th Biennial Conference on Engineering Systems Design and Analysis, 2014.

F. Casella and A. Leva. Modelica open library for power plant simulation: design and experimental validation. In: Proceedings of the 3rd International Modelica Conference, pages 4150, 2003.

F. Casella and F. Pretolani. Fast start-up of a combined-cycle power plant : A simulation study with modelica. In: 6th Modelica Conference, pages 3-10, 2006.

F. P. Incropera, D. P. DeWitt, T. L. Bergman, and A. S. Lavine. Fundamentals of heat and mass transfer. 6 ed. Jefferson City, United States of America: John Wiley \& Sons, Inc, 2007. ISBN 9780470501979.

P. Kloster. Energy optimization on offshore installations with emphasis on offshore combined cycle plants. In: Offshore Europe Conference, 1999.

MathWorks. Global Optimization Toolbox, 2017.
N. Mazzi, S. Rech, and A. Lazzaretto. Off-design dynamic model of a real organic rankine cycle system fuelled by exhaust gases from industrial processes. Energy, 90(1):537$551,2015$.

Ministry of Environment. White Paper on Climate Efforts. Technical report, Norwegian Government, 2012.

R. M. Montañés, S. Ó. GarDarsdóttir, F. Normann, F. Johnsson, and L. O. Nord. Demonstrating load-change transient performance of a commercial-scale natural gas combined cycle power plant with post-combustion co2 capture. International Journal of Greenhouse Gas Control, 63:158-174, 2017.

L. O. Nord and O. Bolland. Steam bottoming cycles offshore challenges and possibilities. Journal of Power Technologies, 92(3):201-207, 2012.

L. O. Nord and O. Bolland. Design and off-design simulations of combined cycles for offshore oil and gas installations. Applied Thermal Engineering, 54(1):85-91, 2013.

Norwegian Ministry of Petroleum and Energy. Emissions to Air. http://www.norskpetroleum. no/en/environment-and-technology/ emissions-to-air/, 2017. [Accessed: 2017-05$15]$.

L. Pierobon, A. Benato, E. Scolari, F. Haglind, and A. Stoppato. Waste heat recovery technologies for offshore platforms. Applied Energy, 136(1):228-241, 2014a.

L. Pierobon, E. Casati, F. Casella, F. Haglind, and P. Colonna. Design methodology for flexible energy conversion systems accounting for dynamic performance. Energy, 68(1):667$679,2014 b$.

S. Quoilin, R. Aumannb, A. Grill, A. Schuster, V. Lemort, and H. Spliethoff. Dynamic modeling and optimal control strategy of waste heat recovery organic rankine cycles. Applied Energy, 88(1):2183-2190, 2011.

L. Riboldi and L. O. Nord. Lifetime Assessment of Combined Cycles for Cogeneration of Power and Heat in Offshore Oil and Gas Installations. Energies, 10(6):744, 2017.

Jairo Rúa. Master thesis: Dynamic modeling and process simulation of steam bottoming cycle. 2017.

Statoil ASA. A Structural Approach to Operational Semantics. Technical report, 2016.

A. Stodola. Steam and Gas Turbines. McGraw-Hill Book Company, Inc., 1927.

Thermoflow Inc. Thermoflex, Version 26.0, 2016. 